\title{
Research Paper \\ Evaluation of Protective Antibody Titer Against HBs Antigen in Students of Gonabad University of Medical Sciences in 2018
}

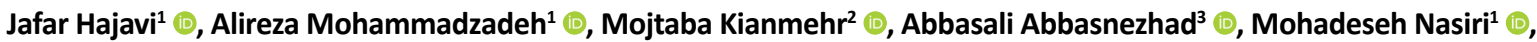 \\ Mahnaz Alie ${ }^{1}$, Zohreh Pirzadeh Moghaddam ${ }^{1}$, Zahra Elahi' ${ }^{1}$, Zahra Jamali ${ }^{1}$, Seyyed Behnam Mazloum Shahri ${ }^{1} \mathbb{C}^{\circ},{ }^{*}$ Seyed \\ Hossein Abtahi Eivary ${ }^{1}$ (1)
}

1.Department of Medical Sciences of Laboratory, Infectious Diseases Research Center, School of Para-Medicine, Gonabad University of Medical Sciences, Gonabad, Iran.

2. Department of Medical Physics, Faculty of Medicine, Gonabad University of Medical Sciences, Gonabad, Iran.

3. Department of Physiology, Faculty of Medicine, Gonabad University of Medical Sciences, Gonabad, Iran.

4. Office of Statistics and Information Technology, Gonabad University of Medical Sciences, Gonabad, Iran.

$\begin{aligned} & \text { Use your device to scan } \\ & \text { and read the article online }\end{aligned}$
Citration Hajavi J, Mohammadzadeh A, Kianmehr M, Abbasnezhad A, Nasiri M, Alie M, et al. [Evaluation of Protective An-
tibody Titer Against HBs Antigen in Students of Gonabad University of Medical Sciences in 2018 (Persian)]. Quarterly of "The
Horizon of Medical Sciences". 2021; 27(4):518-533. https://doi.org/10.32598/hms.27.4.571.3
doi:https://doi.org/10.32598/hms.27.4.571.3

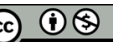

Received: 29 Jan 2021 Accepted: 02 Jun 2021 Available Online: 01 Oct 2021

Key words:

Anti-HBs, Hepatitis

$B$, Medical students, Antibody titer

\section{A B S TR A C T}

Aims Hepatitis B infection is one of the common diseases and the most prevalent communicable virus transferred by blood to the healthcare personnel. Active immunity, through vaccination, is the most effective way to prevent hepatitis B infection. The current study aimed to determine the protective antibody titer against HBs antigen in Gonabad University of Medical Sciences students, Gonabad City, Iran, 2018.

Methods \& Materials The present cross-sectional study was conducted on 416 students of Gonabad University of Medical Sciences. The HBsAb level was determined in blood samples by an Enzyme-Linked Immunosorbent Assay (ELISA) kit made in Iran. Data were analyzed using descriptive statistics like frequency distribution tables and inferential statistics as independent 2-sample t-test and Chi-square test to determine the relationship between variables. The significance level was considered $\mathrm{P}<0.05$.

Findings HBsAb level of 217 cases (51.8\%) was below $10 \mathrm{lU} / \mathrm{mL}, 96(61.3 \%)$ had an HBsAb level between 10 and $100 \mathrm{lU} / \mathrm{mL}$, and in 106 (36.5\%) cases, HBsAb level was above $100 \mathrm{lU} / \mathrm{mL}$. There was no statistically significant difference between the means of HBsAb in terms of gender, age, and body mass index $(\mathrm{P}<0.05)$.

Conclusion In general, more than $50 \%$ of the study participants had mild immunity against hepatitis $B$ viruses. Therefore, in these people, it is recommended to check the antibody titer periodically to ensure immunity against hepatitis $B$.

English Version
1. Introduction
nfectious diseases constitute a significant
health problem in developing and third
world countries, and much of the cost of

health care and clinical research is spent on diagnosing and treating these diseases [1].

Viral hepatitis is highly prevalent due to inflammation of the liver and various viruses, drugs, alcohol and adipose tissue replacement, and other factors [2]. Hepatitis B infection alone is the most important cause of liver disease and the leading cause of hepatitis mortality in Iran [3].

\section{* Corresponding Author:}

Seyed Hossein Abtahi Eivary, PhD.

Address: Department of Immunology, School of Medicine, Gonabad University of Medical Sciences, Gonabad, Iran.

Tel: +98 (915) 5331265

E-mail: hosein.abtahi@gmail.com 
The importance of hepatitis B results from its high prevalence and hepatic and extrahepatic complications [4].

The prevalence of the hepatitis B virus is more than 2 billion people in the world, of which 400 million are chronic carriers of the virus, and every year about 53000 new cases are reported [1]. Approximately $45 \%$ of the world >s population lives in hyperendemic regions (prevalence greater than or equal to $8 \%$ ), $43 \%$ in the mesoendemic areas (prevalence between $2 \%$ and $7 \%$ ), and $12 \%$ in hypoendemic regions (prevalence less than $2 \%$ ) [5].

Factors such as the prevalence of infection, age, sex, weight, genetic structure, individual immune status, underlying diseases, smoking, obesity, differences between vaccines, location and method of vaccine injection, the time elapsed since last vaccine dose, and amount of contact with a positive $\mathrm{S}$ antigen is effective in hepatitis [5].

Hepatitis B virus belongs to the hepadnavirus family [6]. The virus has three major types of antigens: s, c, and e. The presence of HBs antigen is the first sign of infection. This antigen can be detected in $90 \%$ to $95 \%$ of acute cases, and the antibody produced against it has a protective role [6].

HBsAg is the most common indicator used to diagnose hepatitis $\mathrm{B}$. This antigen is present in acute and chronic infections; continued presence and positive $\mathrm{HBsAg}$ for at least 6 months indicates the active state of the infection [7].

The ways of transmission of hepatitis B disease are very diverse, and the commonest way is blood transfusion (blood and blood products) [8]. The effective immune response to the hepatitis $\mathrm{B}$ virus depends on the response of various components of the cellular immune system, including natural killer (NK) cells, CD+4 helper T cells, CD8+ killer T cells, and regulatory T cells. Studies have shown that CD4 and CTL memory cells are active in the presence of low levels of hepatitis B virus DNA for up to 23 years after primary infection $[9,10]$.

Prevention is vital because there is no complete and proper cure for HBV infection [11]. HBV vaccination using a recombinant vaccine with HBs antigen particles is the most effective and safe method of prevention. The vaccination strategy against hepatitis B is based on geographical differences and the epidemiology of hepatitis B. Three doses of the hepatitis B vaccine, which consists only of hepatitis B surface antigen, can produce protective antibodies in $85 \%$ of healthy individuals [12].
Vaccination of hepatitis B worldwide for infants as well as people with high-risk conditions, especially health workers in Iran, began in 1993, and since 2006, vaccination of adolescents under 18 years (born in 1989) was added to the program. Vaccination against hepatitis surface antigen can induce antibody-protective levels in most vaccinated individuals. Meanwhile, despite the very high efficacy of the vaccine, about $5 \%$ to $10 \%$ of people cannot produce antibodies at acceptable levels against hepatitis B surface antigen for various reasons, including genetic factors, immunosuppression, and some specific diseases [13].

Over time, in some vaccinated individuals, the antibody titer decreases [14-16]. Studies in Iran have shown different results in terms of antibody titer. The study performed among clinical medical students of Islamic Azad University of Mashhad showed that the mean antibody titer was 186.5 with a standard deviation of 114.9 units and 10 patients (6.5\%) [17] had no antibody response. Also, in another study, the hepatitis B vaccine was evaluated for immunogenicity in the medical staff of Shahid Madani Hospital in Tabriz. Of the subjects, 32 had no protective titer, 38 had partial protective titer, and 76 had full protective titer [18].

One of the high-risk groups is students who study in health and medical centers who are exposed to this disease due to a lack of sufficient skills in performing treatment processes. On the other hand, reducing the titer of antiHBs by reducing immunity is associated with hepatitis B, and in practice, vaccination programs will not be effective $[19,20]$. Therefore, measuring the titer of immunogenic antibodies in high-risk groups of the community, such as medical staff and students to estimate their immunogenicity and immunity in high-risk groups is of particular importance. Therefore, this study was performed to evaluate the hepatitis B antibody titer in students of Gonabad University of Medical Sciences in 2018.

\section{Materials and Methods}

The current study is a descriptive cross-sectional study in which the study population was students of Gonabad University of Medical Sciences who have entered their clinical internship. An available sampling method was used for this study. The purpose of this study was explained to all students participating in the study. Data collection tools were questionnaires and checklists. All students completed the questionnaires.

The questionnaire included questions related to demographic characteristics and dates of vaccination of stu- 
Table 1. Number of participants in the study by gender and mean titer

\begin{tabular}{|c|c|c|c|c|}
\hline Gender & Frequency & Relative Frequency & Mean Titer & Titer Standard Deviation \\
\hline Female & 256 & 61.5 & & \pm 70.42 \\
\hline Male & 160 & 38.5 & & \pm 49.53 \\
\hline Total & 416 & 100.0 & & \\
\hline
\end{tabular}

dents, and a checklist containing weight and test results for hepatitis B antibody titer. The questionnaire also includes information, such as educational level, Body Mass Index (BMI), smoking, history of hepatitis in family members, history of corticosteroids, history of radiotherapy, chemotherapy, leukemia, lymphoma, blood transfusion, history of needle contact, history of suspected, unprotected sexual contact, and had a history of kidney and liver failure . The formal validity and content validity of data collection tools were determined by five faculty members. Information about all students was obtained from the administrators of the relevant group. First, for serum analysis, $5 \mathrm{~mL}$ of blood samples were taken from each person and then the samples were placed in a centrifuge and their serum was separated. The isolated sera were all frozen at $-18^{\circ} \mathrm{C}$. To determine the degree of immunity to hepatitis B infection, anti-HBs titration was measured by leading medical laboratory kits in the immunology laboratory of the paramedical school. The amount of hepatitis B antibody titer was quantitatively determined by the ELISA method. If the antibody titer was less than $10 \mathrm{IU} / \mathrm{mL}$, the immunity was weak. If the antibody titer was between 10-100 IU/ $\mathrm{mL}$, the immunity was moderate, and when the antibody titer was more than $100 \mathrm{IU} / \mathrm{mL}$, the safety was considered desirable. After data collection, the data were entered SPSS software version 18. Data were analyzed using descriptive statistical methods in the form of frequency distribution tables and analyzed by the Kruskal-Wallis, 2-sample independent t-test, and Chi-square test to determine the relationship between variables.

\section{Results}

According to the study population, students from different disciplines were included in the study, which is listed separately in the (Table 1). Also, individuals were divided into two groups based on vaccine injection: vaccinated and unvaccinated.

Participants in the study were divided into three groups based on hepatitis B antigen-antibody titer: weak (less than $10 \mathrm{IU} / \mathrm{mL}$ ), moderate (between 10 to $100 \mathrm{IU} / \mathrm{mL}$ ), and favorable (more than $100 \mathrm{IU} / \mathrm{mL}$ ). Then, the titer obtained from the antibody assay is calculated based on gender, age, and status of the titer (weak, moderate, and favorable) and is given separately in the Table.

Out of the total students participating in the study, 106 had a favorable status in terms of antibodies against hepatitis B antigen, and also that the optimal status of antibody titer was higher in women than men (Table 2). The classification of different groups based on age has been done in four age groups, and the most desirable results of antibody titer have been observed in the age group of 18-21 years, and the important point is that the same group in terms of the weakest titer has the most among other age groups and is statistically significant (Table 3 ).

Participants were also divided into 3 groups based on body mass index, and their titers were categorized as desirable, moderate, and weak. The results of which are given in Table $4(\mathrm{P}=0.723)$. Also, the results of analysis based

Table 2. Frequency of antibody titer based on sex and titer status

\begin{tabular}{cccccc}
\hline \multirow{2}{*}{ Gender } & & No. (\%) & & & \\
\cline { 2 - 5 } & Moderate & Favorable & Total & Total & P \\
\hline Female & $118(46.1)$ & $64(25.0)$ & $74(28.9)$ & $256(100)$ & 0.02 \\
Male & $96(60.0)$ & $32(20.0)$ & $32(20.0)$ & $160(100.0)$ & \\
& & & & $\begin{array}{l}\text { Quarterly of } \\
\text { The Horizon of Medical Sciences }\end{array}$
\end{tabular}


on the titer and body mass index showed the best favorable titer in people with body mass index exists in the category of 20-26 years. As shown in Table 5, Levene's test was used to check the equality of the variance of the two groups. The value of $\mathrm{P}$ is less than 0.001 ; therefore, the equality of variances is rejected, but in the mean equality of the two groups, the value of $\mathrm{P}=0.016$ is less than 0.05 .

\section{Discussion}

Hepatitis B virus is one of the most common and important causes of acute and chronic hepatitis, liver cirrhosis, and cancer in the world [20]. One of the main ways to prevent hepatitis B infection is to be vaccinated and develop proper immunity against it. A high level of safety of personnel working in hospitals and health centers can reduce the incidence of infections among these people [21]. Medical students who come to hospitals as interns are exposed to all kinds of patients> secretions; they are exposed to this disease due to not having enough skills in performing treatment processes, so immunization and immunosuppression after vaccination in this group are important.

The current study was conducted among 416 students studying at Gonabad University of Medical Sciences in 2018. The current study showed that 106 participants in the study have a favorable status in terms of antibody titer against hepatitis B. In the study conducted by Suleiman and associates on 139 personnel working in Farshchian and Army medical centers in Hamedan, $5.1 \%$ of the staff had antibody levels below $10 \mathrm{IU} / \mathrm{mL}$ but in \%51.8 (217 people), the antibody level was below 10 [22]. These differences may be due to differences in the history of vaccination between the two groups. In our study, the interval between vaccination time and antibody titer is higher than the same time in the study of Suleiman et al. Also, in our study, 25.3\% (96 people) had antibody levels above 100 $\mathrm{IU} / \mathrm{mL}$ which was higher than the study of Suleiman and associates with $3.1 \%$. Regarding the difference between those with a titer above 100 , it can be said that due to the younger students, they had higher immunogenicity.

In our study, $51.8 \%$ of the participants in the study were without the necessary immunity. The study of Suleiman and associates also showed a decrease in the level of safety in one-third of the subjects. A study by Rostami et al. in Tabriz in 100 at-risk hospital staff showed that $11 \%$ of antibody titers were less than 10 (unsafe) $14 \%$ of antibody titers were between 10 and 100 (relative safety) and 75\% had antibody titers greater than 100 (safe). They were 3 times safer than our study, but $51.8 \%$ were unsafe, which is about five times more than the study of Jouneghani et al. [23].

Consistent with the study of Darvish Moghadam et al. andthe study of Amini et al., the current study showed that the level of antibodies decreases over time after vaccination $[24,25]$. The level of immunity of Iranian health center staff in various studies has been reported from $50 \%$ to $90 \%$. In the study of Sarkari et al. in Yasuj hospitals, out of 212 hospital staff who were randomly selected, more than $85 \%$ had the necessary immunity [21]. In contrast, in our study, immunity was $25.3 \%$ and in the study of Momen Heravi and associates which was performed in Shahid Beheshti Hospital in Kashan, 79.8\% of people had an acceptable level of safety [26].

In the study of Khodavisi et al., the immune status of hepatitis in the study population indicates that $66 \%$ had good immunity, $28 \%$ had poor immunity and $6 \%$ of students lacked immunity [27]. Contrary to these results, in our study, the immunity status was poor in $51.8 \%$, favorable in $25.3 \%$, and moderate in $22.9 \%$. In total, $48.8 \%$ of the subjects had good immunity to hepatitis B in the study. But in the study of Khodavisi et al., Bayas et al. and Janbakhsh, the immunity status was 94\%, 97\%, and $96.6 \%$, respectively, which were higher and safer than our study $[28,29]$. It may depend on the type of vaccine used, for which information is not available

Table 3. Antibody titer based on age and titer

\begin{tabular}{ccc}
\hline Age & No. (\%) & P \\
\hline $21-18$ years & $263(62.9)$ & \\
$24-22$ years & $138(33.0)$ & $<0.001$ \\
$27-25$ years & $11(2.6)$ & \\
$<27$ year & $6(1.4)$ & \\
Total & $416(100.0)$ & \\
\hline
\end{tabular}


Table 4. Relationship between titer category and body mass index

\begin{tabular}{|c|c|c|c|c|c|c|}
\hline \multirow{2}{*}{ Variables } & & \multicolumn{3}{|c|}{ Titer Category } & \multirow{2}{*}{ Total } & \multirow{2}{*}{$\mathbf{P}$} \\
\hline & & Weak & Moderate & Favorable & & \\
\hline \multirow{4}{*}{$\begin{array}{l}\text { Classification based on } \\
\text { body mass index, } \mathrm{kg} / \mathrm{m}^{2}\end{array}$} & $>20$ & 59 & 22 & 32 & 113 & \\
\hline & $26-20$ & 120 & 56 & 55 & 231 & \\
\hline & $30-26$ & 23 & 12 & 16 & 51 & 0.723 \\
\hline & $<30$ & 9 & 4 & 2 & 15 & \\
\hline \multicolumn{2}{|l|}{ Total } & 211 & 94 & 105 & 410 & \\
\hline
\end{tabular}

Our study did not show a significant relationship between gender and immune status against hepatitis, but this relationship was observed between the age of participants in the study and antibody titer so that the most favorable group in terms of antibody titer in the age group of 1821 was observed (48 people). On the other hand, in this age group, 60 people had a weak immune status which is statistically significant. Consistent with our study, Zamani et al. also showed a significant relationship between age and duration of vaccine with antibody titer [16]. There is conflicting information about the effect of gender on immunosuppression. Consistent with our study, the study of Khodavisi et al. as well as Zamani et al. both in the field of the relationship between gender and the immune response, showed that there is no significant relationship between gender and the immune response [16, 27]. Contrary to our study, Ferraz et al. reported a higher titer of anti-hepatitis antibody in women in their study [30], but Mansouriss study showed that men responded better to the vaccine $[31,32]$.

Rostami>s study also showed that antibody titer had a significant relationship with gender and smoking, which was contrary to the results of our study. In addition, the study of Baba Mahmoudi et al . did not show a relation- ship between age and immune response, although in our study, there were the most immune people in the age group of 21-18 years, this relationship was not significant [33].

The study of Haji Bagheri et al. similarto our research, did not find a relationship between age and weight with serum levels of antibodies against HBs [34]. Similar to our study, Pera et al. did not find a significant relationship between body mass index and antibody titer [35]. But unlike our study, Heidari et al. showed a significant relationship [36].

In the study of Nooshirvanpour et al., a significant relationship was observed between gender and antibody titer and this titer was higher in women, but in our study, no significant relationship was observed between gender and antibody titer [37]. Studies of Izadpanah et al. and Dervishes et al. did not show a relationship between gender and antibody titer [38]. It is possible that the study method, antibody measurement method, sensitivity, and specificity of the kits used can be among the factors for observing different responses and thus comparing them.

\section{Conclusion}

Prevention is an important issue in public health, and due to the high risk of students, to ensure the effective

Table 5. The relationship between titer level and high and low antibody titers in the study

\begin{tabular}{|c|c|c|c|c|c|c|c|c|}
\hline \multirow{2}{*}{ Titer } & \multicolumn{2}{|c|}{$\begin{array}{l}\text { Levene's Test for Equal- } \\
\text { ity of Variances }\end{array}$} & \multirow{2}{*}{$\mathbf{t}$} & \multirow{2}{*}{ df } & \multirow{2}{*}{$\begin{array}{c}\text { Sig/ } \\
\text { (2-tailed) }\end{array}$} & \multirow{2}{*}{$\begin{array}{l}\text { Mean Dif- } \\
\text { ference }\end{array}$} & \multicolumn{2}{|c|}{$\begin{array}{l}\text { 95\% Confidence Interval } \\
\text { of the Difference }\end{array}$} \\
\hline & $\mathbf{F}$ & Sig. & & & & & Lower & Upper \\
\hline $\begin{array}{c}\text { Titer } \\
\text { Equal variances assumed }\end{array}$ & 16.392 & 0.000 & 2.300 & 414 & 0.022 & 20.88 & 3.033 & 38.729 \\
\hline $\begin{array}{c}\text { Equal variances not } \\
\text { assumed }\end{array}$ & & & 2.419 & 389.345 & 0.016 & 20.88 & 3.91 & 37.852 \\
\hline
\end{tabular}


level of antibodies after childhood vaccination, it is necessary to check the antibody titer against HBsAg before entering different wards of the hospital.

\section{Ethical Considerations}

\section{Compliance with ethical guidelines}

This study was approved by the Ethics Committee in Biomedical Research of Gonabad University of Medical Sciences (Cde: IR.GMU.REC.1397.106). Ethical considerations for conducting this research have been observed throughout the research process.

\section{Funding}

This study was conducted with the financial support of the Vice-Chancellor for Research and Technology of Gonabad University of Medical Sciences (Code: 101641-A).

\section{Authors' contributions}

The main idea, study design, data collection, and specialized experiments: Seyed Hossein Abtahi and Jafar Hajavi; Data collection and study design: Alireza Mohammadzadeh, Mojbati Kian Mehr, and Abbas Ali Abbasneja; A critical review of the manuscript and final review: Jafar Hajavi, Seyed Hossein Abtahi, Alireza Mohammadzadeh, Mojbati Kian Mehr and Abbas Ali Abbasnejad; Data analysis: Seyed Behnam Mazlum Shahri; Data collection: Mohadeseh Nasiri, Mahnaz Aali, Zohreh Pirzadeh Moghadam, Zohreh Elahi and Zahra Jamali.

\section{Conflicts of interest}

The authors declared no conflict of interest.

\section{Acknowledgements}

The authors would like to express their appreciation and gratitude to students and other contributors who cooperate in carrying out this project. 
This Page Intentionally Left Blank 


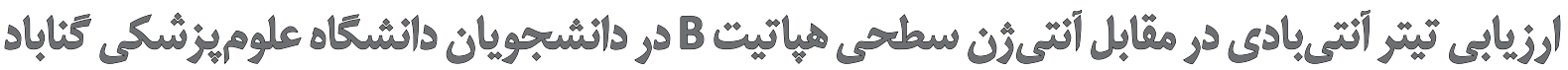

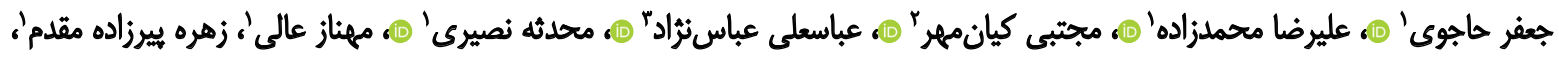

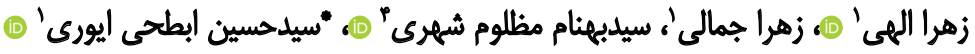

ا.كروه آموزشى علوم آزمايشكاهى، مركز تحقيقات بيمارى هاى عفونى، دانشكده هيرايزشكى، دانشكاه علوم هز شكى كناباد، كناباد، ايران.

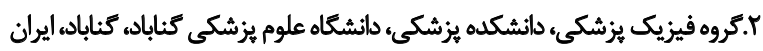

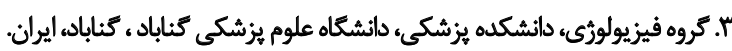

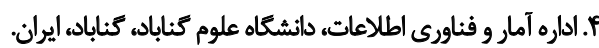

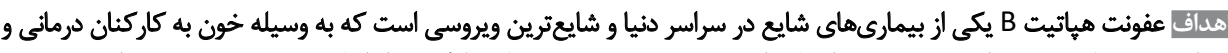

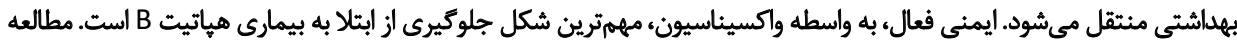

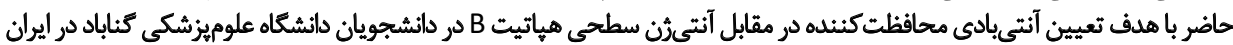

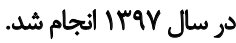

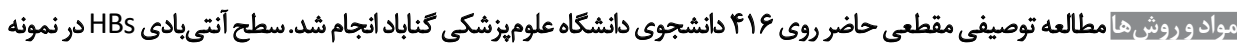

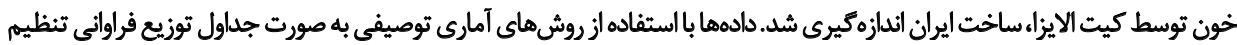

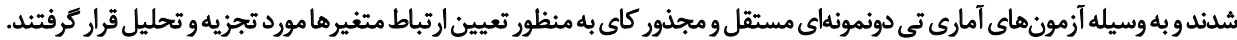

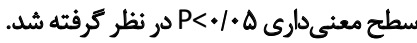

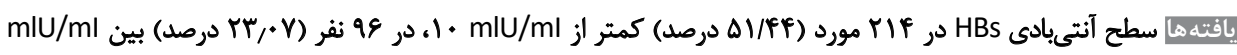

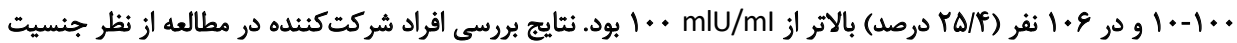

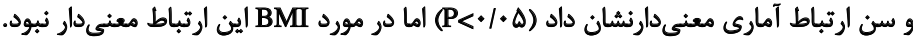

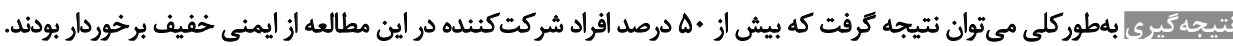

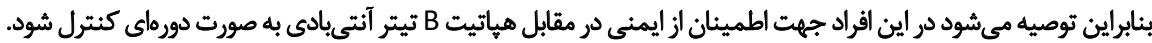

$$
\begin{aligned}
& \text { تاريخ دريافت: •| بهمن } 99
\end{aligned}
$$

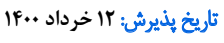

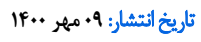

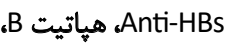
دانشجويان علوميزشكي، تيتر آنتيبادي

هياتيت B 'به تنهايى مهمرترين علت بيمارى كبدى و اصلىترين

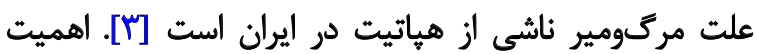

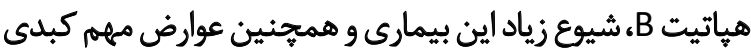
بيمارىهاى عفونى در كشورهاى جهان سوم ودر حال توسعه،

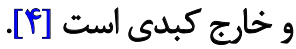
ميزان ابتلا به ويروس هياتيت B در دنيا، بيش از ب بيليون نفر

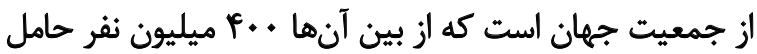

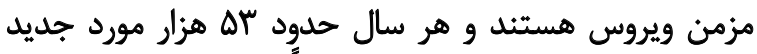

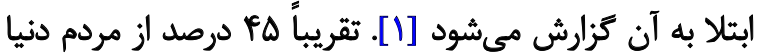

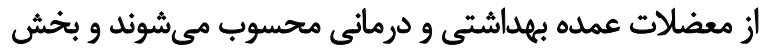

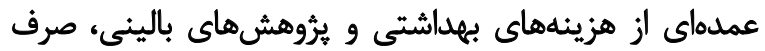

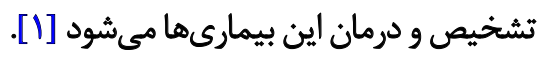
هياتيتهاى ويروسى شيوع بالايى دارند كه به علت التهاب

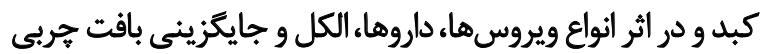

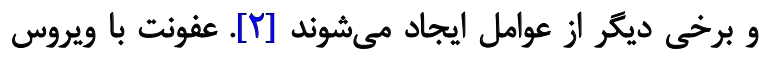

1. Hepatitis B Virus (HBV) 


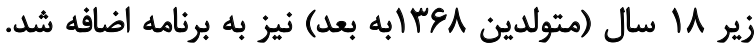

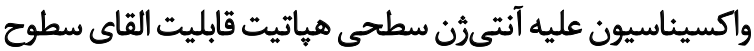

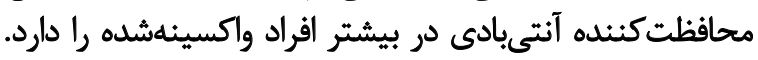

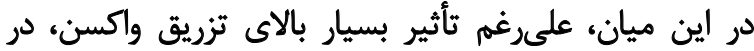

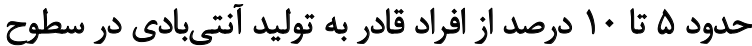

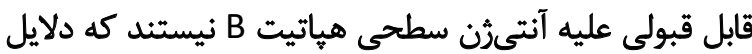

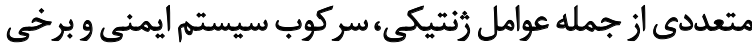

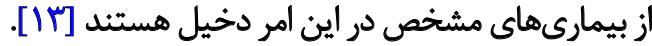
يس إز كذشت زمان، در تعدادى از افراد واكسينهشدها،

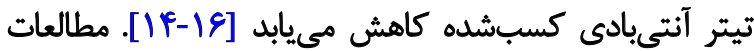
انجامشده در ايران نتايج متفاوتى را از نظر تيتيتر آنتى داديادى نشاني

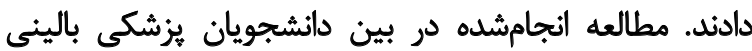

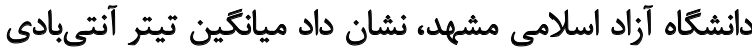
آنج

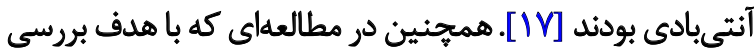

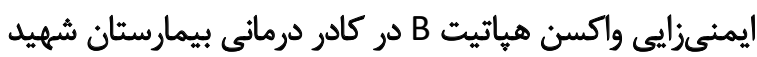

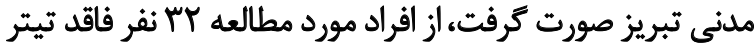

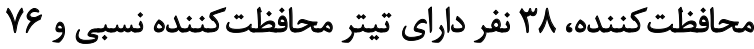
نفر داراي تيتر محافظت كنينده كامل بودند [1/11]. يكى از گروههاى در معرض خطر، دانشجويانى هستند كه در

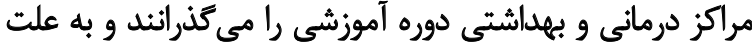

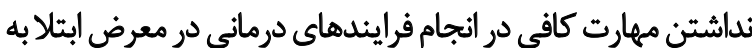

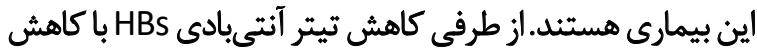

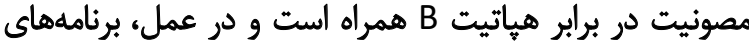

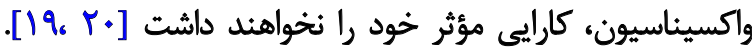

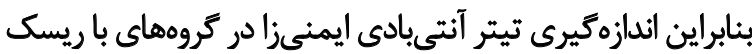

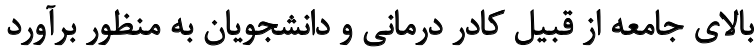

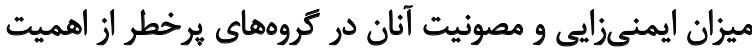

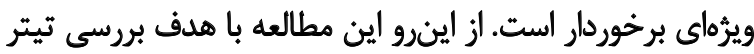

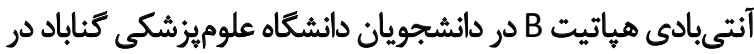

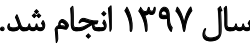

\section{مواد و روش ها}

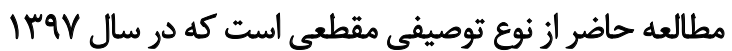

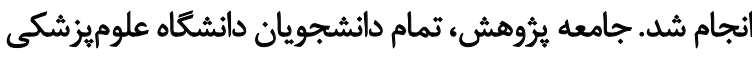

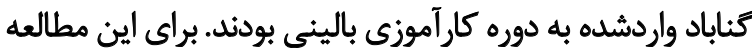

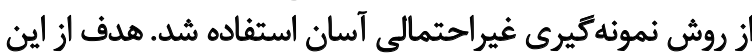

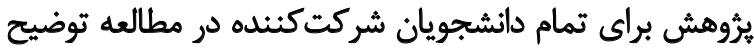

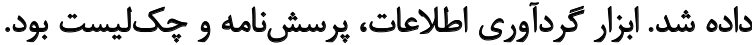
تمام دانشجويان يرسشنامه تهيهشده راتئ تكميل كردند. ورسش نامه شامل سؤالاتمربوط بهمشخصات جمعيتشناختي

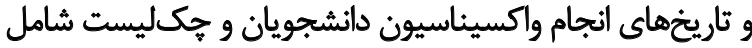
وزن ونتيجه آزمايش ميزان تيتر آنتى بادى هياتيت B بود. همجنين

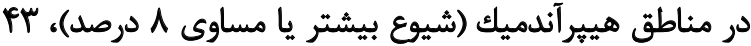

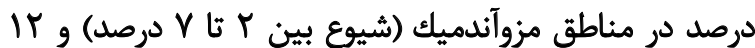

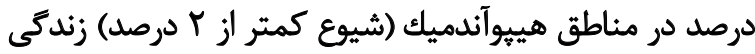

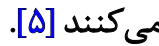

عواملى همجيون شيوع عفونت، سن، جنس، وزن، ساختار

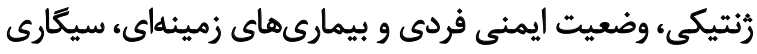

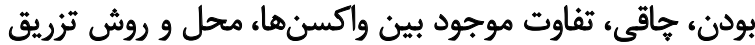

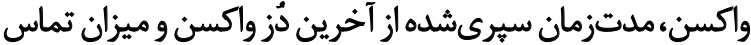

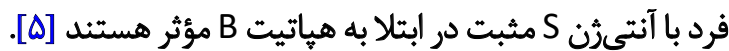

ويروس هياتيت B متعلق به خانواده هيادناويروس است [ع] (S).

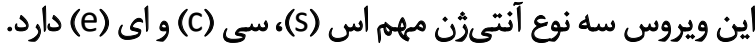

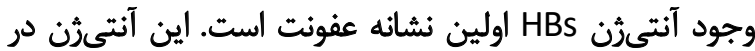

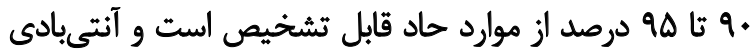

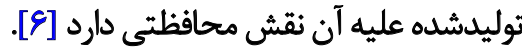

شايعترين شاخص است كه در تشخيص هياتيت BBsAg به رانه

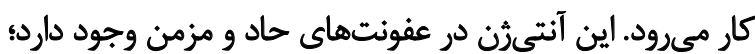
تداوم حضور و مثبت باقى ماندن

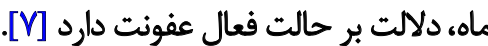

راهماي انتقال بيمارى هياتيت B بسيار متنوع است و بيشترين

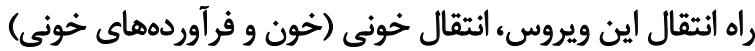

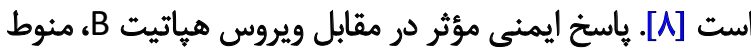

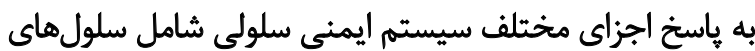

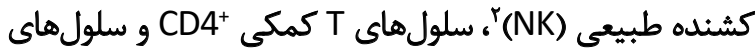

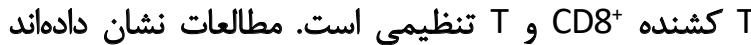

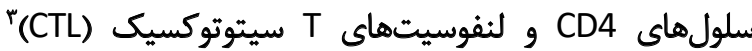
خاطرهاى در حضور سطح جايين DNA ويروس هياتيت B

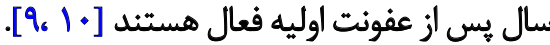
از آنجايي كه درمان مناسب و كاملى براى عفونت HBV وجود

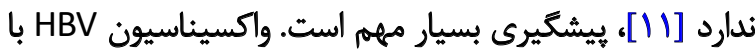

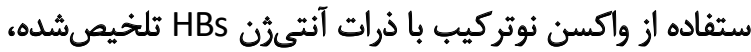

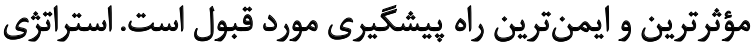

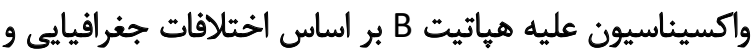

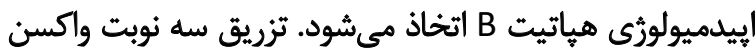

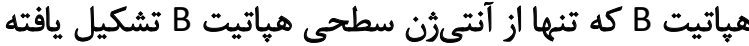

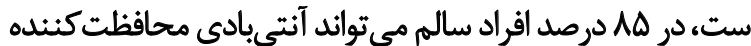

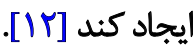

واكسيناسيون هياتيت B سراسرى نوزادان و همجنين إرين افراد

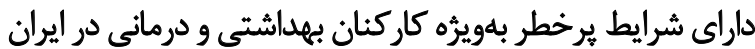

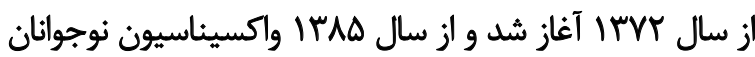

2. Natural Killer (NK) cells

3. Cytotoxic T Lymphocytes (CTL) cells 
جدول ا. تعداد افرادكنيده شركت كنينده در مطالعه به تفكيك جنسيت و ميانكين تيتر

\begin{tabular}{|c|c|c|c|}
\hline 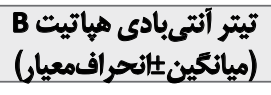 & فراوانى نسبى (درصد) & فراوانى (تعداد) & جنسيت \\
\hline $\mathrm{mlU} / \mathrm{ml} \cdot r V / q Y \pm \mu \mathrm{T} /$ & $\Delta / 81$ & TAS & ن \\
\hline $\mathrm{mlU} / \mathrm{ml} \mathrm{V} \cdot / \mathrm{W} \pm \Delta \mathrm{r} / \mathrm{Fq}$ & $\Delta /{ }^{\prime} A$ & 18. & مرد ل \\
\hline- & $1.0 \%$ & fie & جمع \\
\hline
\end{tabular}

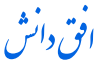

روش هاى آمارى توصيفى به صورت جداول توزيع فراوانى ثنظيم

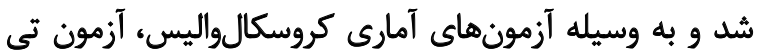

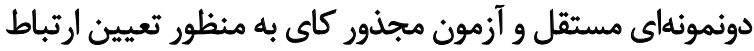
متغيرها مورد تجزيه و تحليل قرار كرفت.

Lavil

جامعه مورد مطالعه دانشجويان دانشكاه علوم يزشكى كناباد

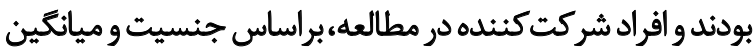
تيتر خود در جدول شماره إن آورده شدهاند.

افراد شركت كنيده در مطالعه بر اساس تيتر آنتىبادى هياتيت

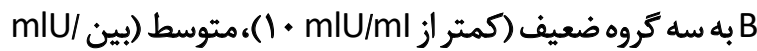

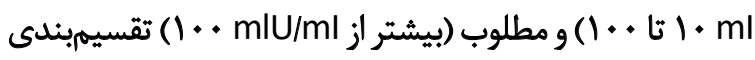

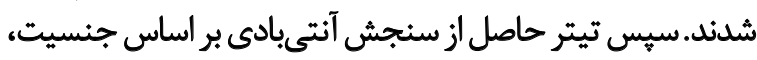
سن و شاخص توده بدنى مورد بررسى قرار ترفت.

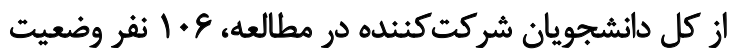

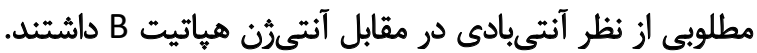

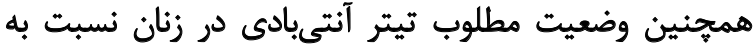

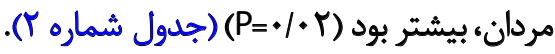

دانشجويان بر اساس سن در جهار تروه سنى دستهبندى شندئد

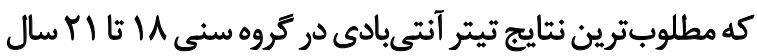

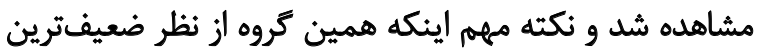

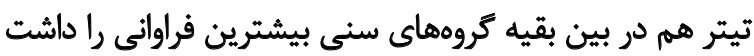

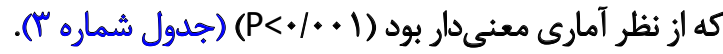

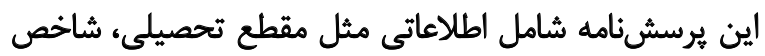

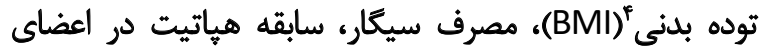

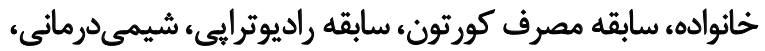

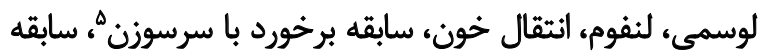

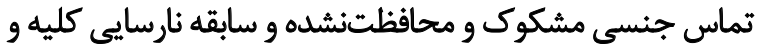

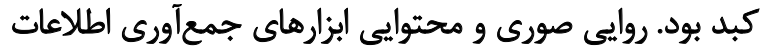

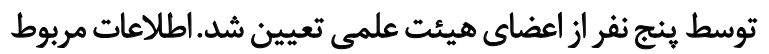

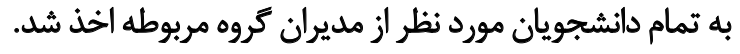

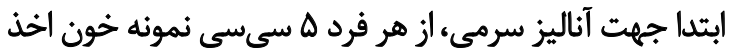

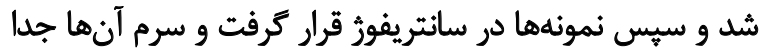

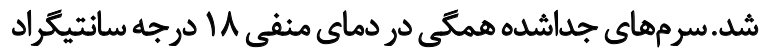

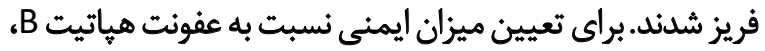

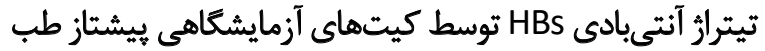

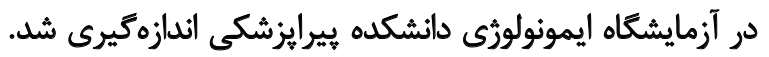

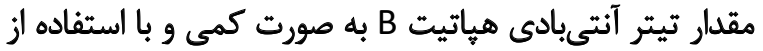

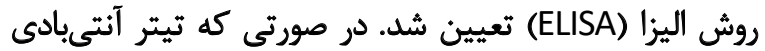

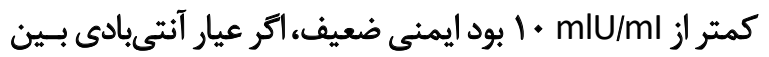
باز m/U/ml بيش از mlU/ml • •. بود، ايمنى مطلوب محسوب شد.

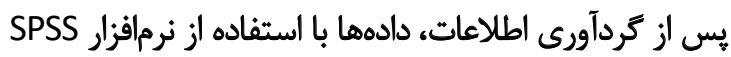

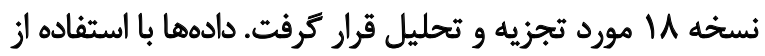

4. Body Mass Index (BMI) 5. Needle stick

جدول Y. بررسى وضعيت تيتر آنتيادي هياتيت B بر اساس جنسيت

\begin{tabular}{|c|c|c|c|c|c|}
\hline \multirow{2}{*}{ سطح معنى دارى } & \multirow{2}{*}{ 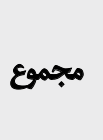 } & \multicolumn{3}{|c|}{ وضعيت تيتر أنتىبادى هياتيت B، تعداد (درصد) } & \multirow{2}{*}{ جنسيت } \\
\hline & & 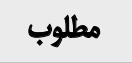 & 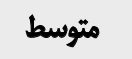 & ضعيف & \\
\hline \multirow{3}{*}{.1 .4} & TAS & $\operatorname{Ve}($ YNQ) & $g \varphi(T \Delta / \cdot)$ & $1 \mathrm{M}(\% \& / 1)$ & ن \\
\hline & 19. & $\pi(r \cdot 1 \%)$ & $\pi(r \cdot \%)$ & $\vartheta(\varepsilon .1 \cdot)$ & 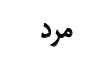 \\
\hline & pie & 1.8 & $\vartheta$ & rif & مجموع \\
\hline
\end{tabular}


جدول بل. بررسى وضعيت تيتر آنتىبادى هياتيت B بر اساس كروهبئدى سنى

\begin{tabular}{|c|c|c|c|c|c|}
\hline \multirow{2}{*}{ 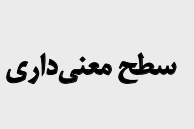 } & \multirow{2}{*}{ 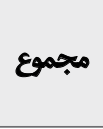 } & \multicolumn{3}{|c|}{ وضعيت تيتر أثتىبادى هياتيت B، تعداد (درصد) } & \multirow{2}{*}{ كروابندى سنى (سال) } \\
\hline & & 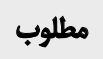 & 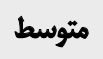 & ضعيف & \\
\hline \multirow{5}{*}{$<+1 . \cdot 1$} & TEY & $\Delta \cdot$ & 9. & lar & $|A-r|$ \\
\hline & irv & ra & r. & $\Delta q$ & $r r-r f$ \\
\hline & 11 & 8 & $r$ & r & $r \Delta-T_{Y}$ \\
\hline & 8 & r & r & 1 & 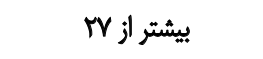 \\
\hline & ple & 1.9 & $q$ & rif & مجموع \\
\hline
\end{tabular}

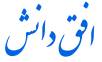

بهداشتى درمانى مى تواند سبب كاهش موارد آلودگى در ميان

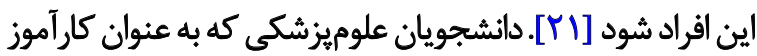

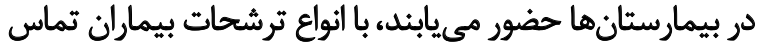

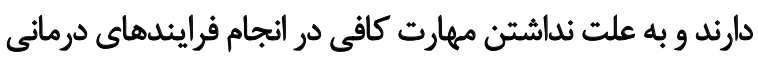

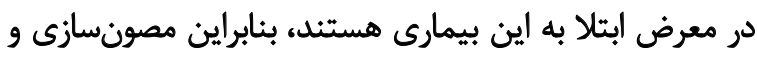

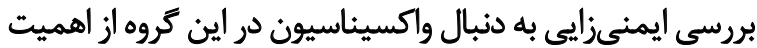
ويزولى برخوردار است.

مطالعه حاضر بين عأ نفر از دانشجويان مشغول به تحصيل

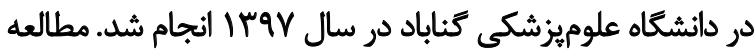

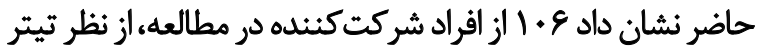

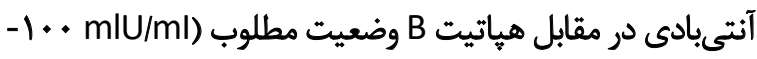

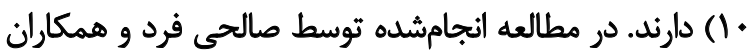

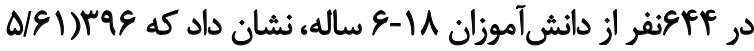

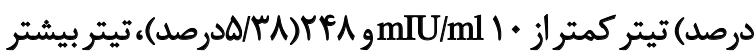

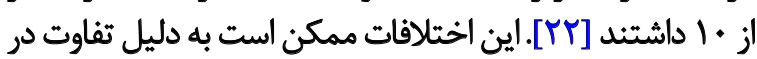

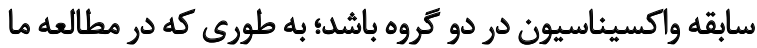
فاصله بين زمان واكسيناسيون و انجام تيتر آنتىبادى نسبت بكائ دريه
همجنين افراد شركت كنئده بر اساس شاخص توده بدنى به سه

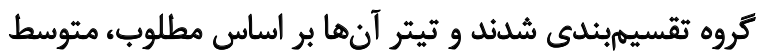

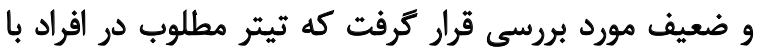

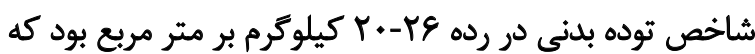

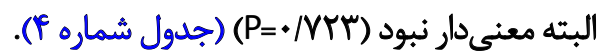
همانطور كه در جدول شماره ها آورده شده است از آزمون

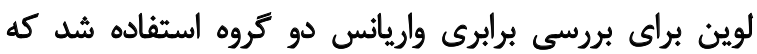

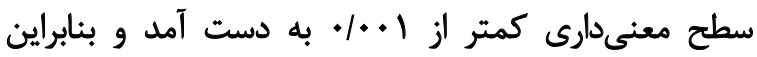

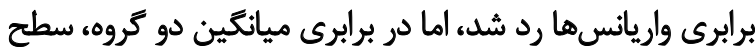

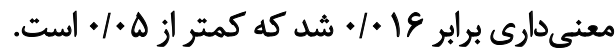

ثs

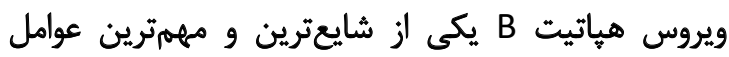

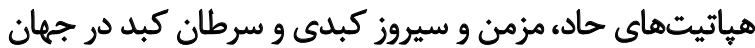

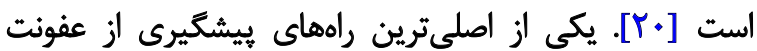

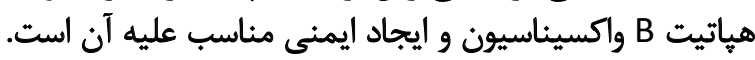

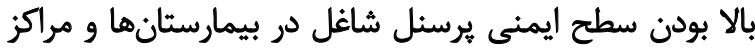

جدول P. بررسى وضعيت تيتر آنتىبادى هياتيت B بر اساس دستهبندى شاخص ثوده بلنى

\begin{tabular}{|c|c|c|c|c|c|}
\hline \multirow{2}{*}{ سطح معنى داري } & \multirow{2}{*}{ هجموع } & \multicolumn{3}{|c|}{ وضعيت تيتر أنتىبادى هياتيت B، تعداد (درصد) } & \multirow{2}{*}{ 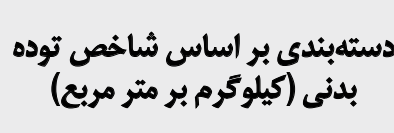 } \\
\hline & & مطلوب & متوسط & ضعيف & \\
\hline \multirow{5}{*}{ M MTr } & 111 & $\pi$ & rr & $\Delta 9$ & كمتر از ب r r \\
\hline & וM & $\Delta \Delta$ & $\Delta$ & ir. & $r \cdot-r g$ \\
\hline & (1) & 18 & ir & m & re-r. \\
\hline & 10 & r & $p$ & 9 & بيشتر از +r \\
\hline & pl. & 1.0 & qp & $M$ & مجموع \\
\hline
\end{tabular}

أن 
جدول ه. نشاندهئده ارتباط بين ميزان تيتر و تيترهاى بالاو وايين آنتىبادى در مطالعه

\begin{tabular}{|c|c|c|c|c|c|c|c|c|}
\hline \multicolumn{2}{|c|}{ فاصله اطمينان 9 درصد } & \multirow{2}{*}{ مياتكَين } & \multirow{2}{*}{$\begin{array}{c}\text { Sig/ } \\
\text { (2-tailed) }\end{array}$} & \multirow[t]{2}{*}{ df } & \multirow[t]{2}{*}{$\mathbf{t}$} & \multicolumn{2}{|c|}{ أزمون لوين براى برابرى } & \multirow{2}{*}{ ميزان تيتر } \\
\hline 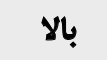 & كايين & & & & & Sig/ & $\mathbf{F}$ & \\
\hline$n \pi / \mu$ & $\cdot \pi / r$ & MT. & $\cdot r r / *$ & fif & $r+\infty / r$ & $+\infty+1 /$ & พqY/\\
& & فرض برابرى واريانس ها \\
\hline ADYTYY & १)/ & Wr. & $.19 \%$ & $m e \Delta / r 1 q$ & $P 19 / r$ & & & فرض نابرابرى واريائس ها \\
\hline
\end{tabular}

أنقانث

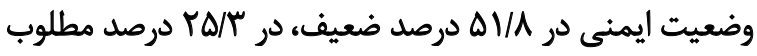

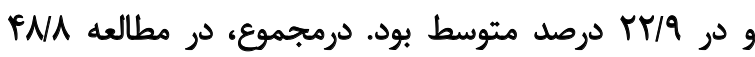

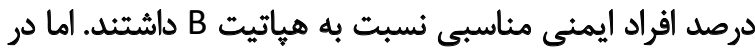

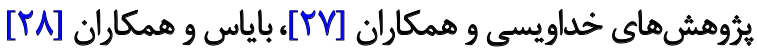

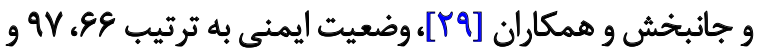

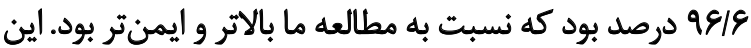

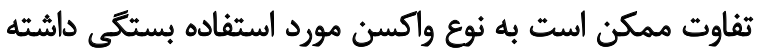
باشد كه اطلاعات آن در دستر آن نوع نيست

مطالعه ما ارتباط معنى دارى بين جنسيت و وضعيت ايمنى و

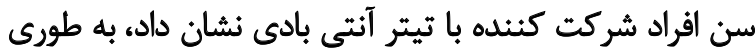

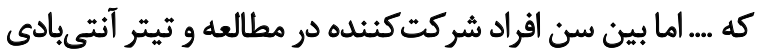

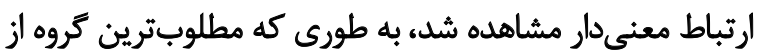

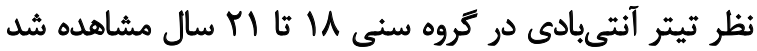

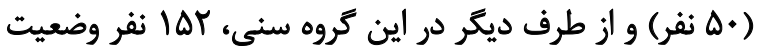

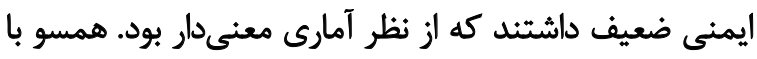

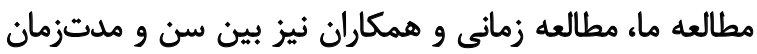

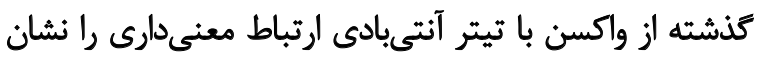

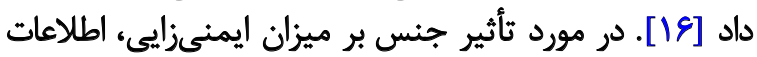

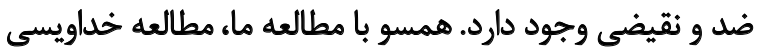

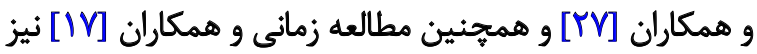

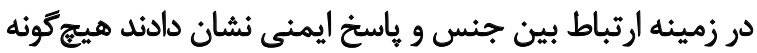

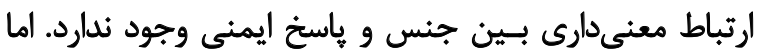

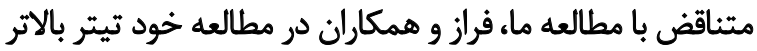

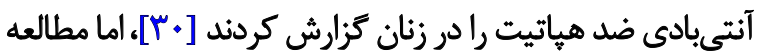

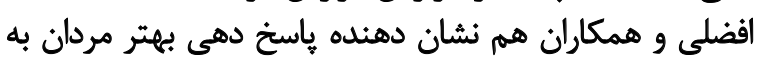

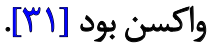

همجنين مطالعه رستمى و همكاران [بان] نشان داد عيار

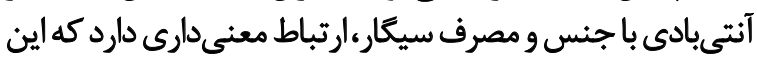

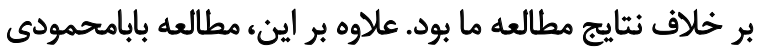

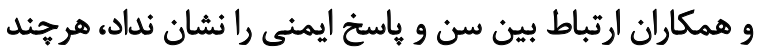

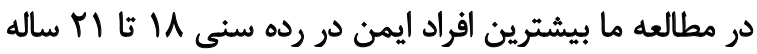
وجود داشت، اين ارتباط در مطالعه ما معني دار و در مطالعه مابيا

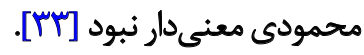

همين زمان در مطالعه سليمان و همكاران بيشتر است. همجنين

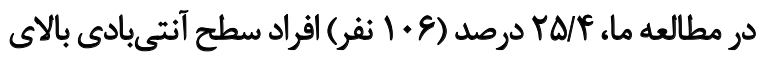
بال mlU/ml

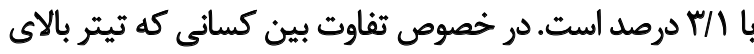

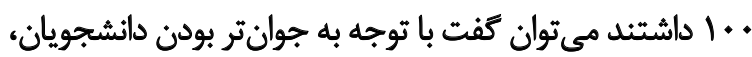

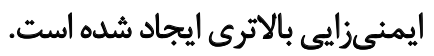

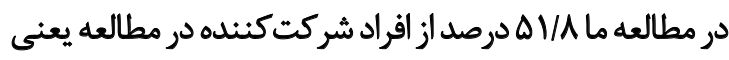
صالج TIF

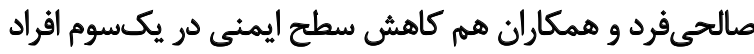

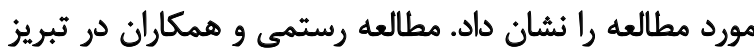

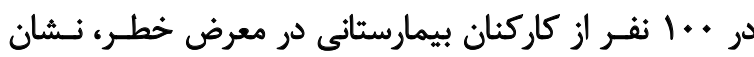

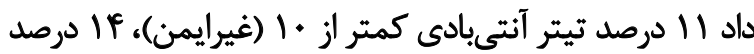

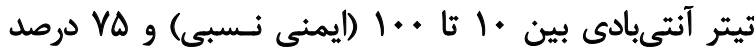

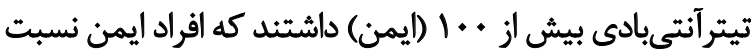

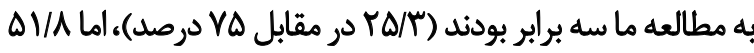

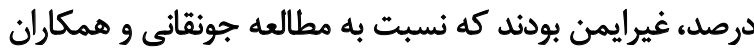

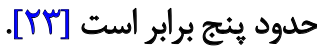

همسو با مطالعه درويش مقدم و همكاران و نيز مطالعه امينى

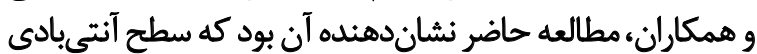

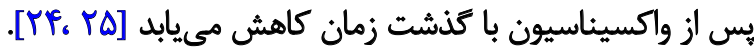

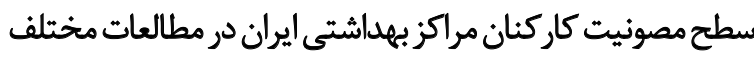
از •م تأ •ج درصد كزارش شده است. در مطالعه سركارى و و

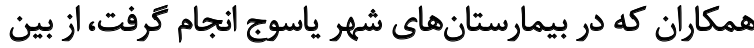

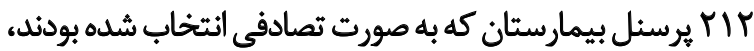

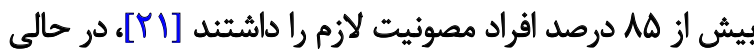

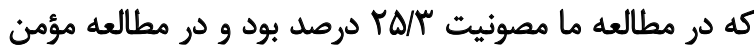

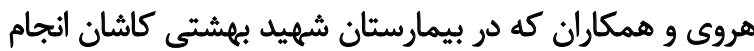

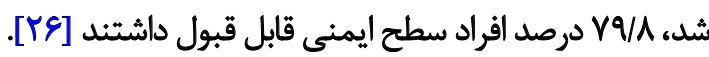
در مطالعه خداويسى و همكاران در مورد وضعيت ايمنى

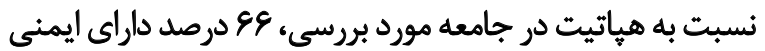

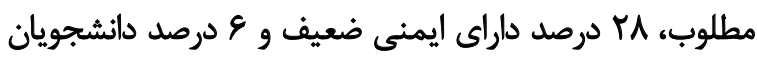

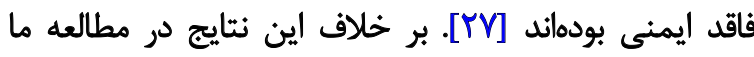


نهايي: جعفر حاجوى، سيد حسين ابطحى، عليرضا محمدزاده،

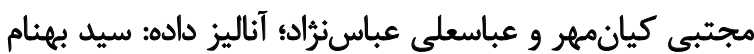

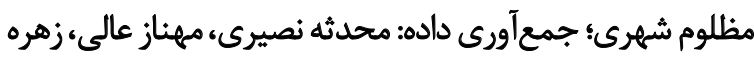

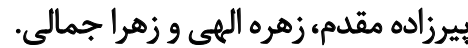

$$
\text { ثقارض منافع }
$$

نويسئدكان اين مقاله اعلام مى دارند كه هيجكونه تعارض

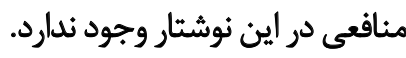

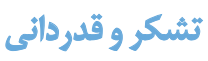

نويسندكان و مجريان طرح مراتب تقدير و تشكر خود را از تمام

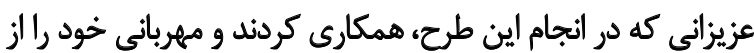

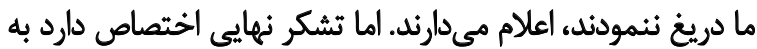

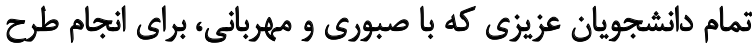

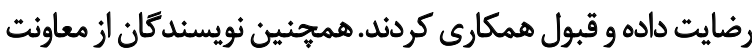

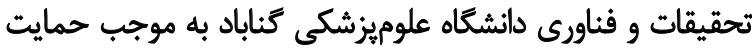
مالى و معنوى در انجام اين طرح كمال تقدير و تشكر را دارند.

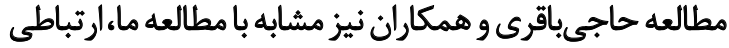

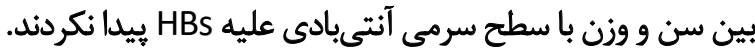

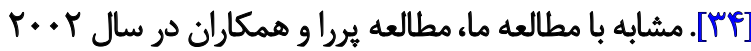

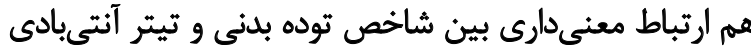

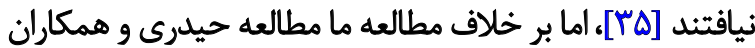

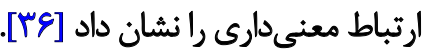

در مطالعه نوشيروانيور و همكاران رابطه معنى دارى بين

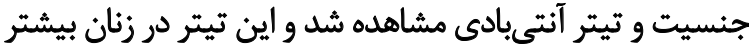

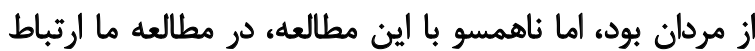

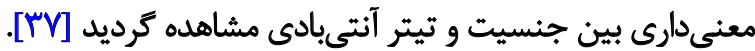

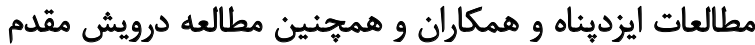

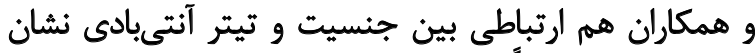

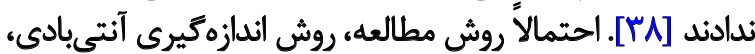

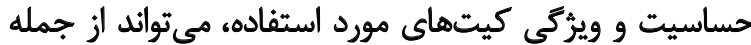
عوامل مشاهده باسخهاى غيريكسان و درنتيجه مقايسه آنها

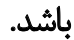

\section{تيجيلمَيرى}

كا توجه به نتايج مطالعه حاضر، با توجه به اينكه با افزايش سن

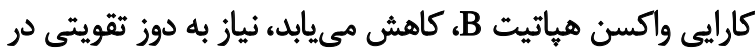

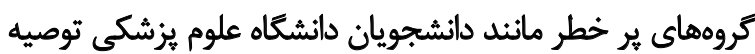

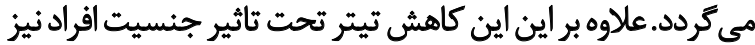

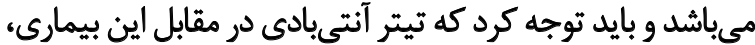

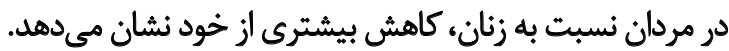

مالاحظات اخلاقي

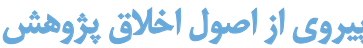

اين مطالعه مصوب كميته اخلاق در يرؤيشهاي

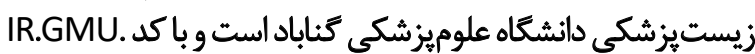
إن. FEC

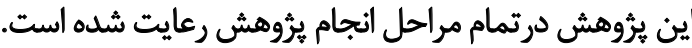

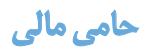

اين مطالعه با حمايت مالى معاونت تحقيقات و فناورى (با كد

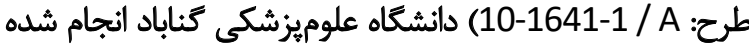
است.

\section{مشاركت نويسندكّان}

ايده اصلى، طراحى مطالعه، كردآورى اطلاعات و انجام

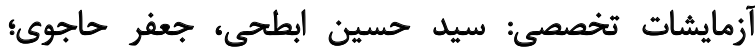

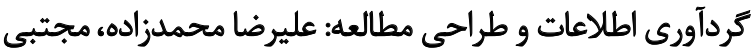

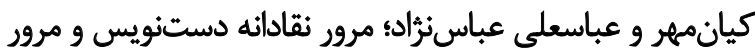




\section{References}

[1] Weinbaum CM, Mast EE, Ward JW. Recommendations for identification and public health management of persons with chronic hepatitis B virus infection. Hepatology. 2009; 49(5 Suppl):S35-44. [DOI:10.1002/ hep.22882] [PMID]

[2] Alter MJ. Epidemiology of hepatitis $B$ in Europe and worldwide. Journal of Hepatology. 2003; 39 Suppl 1:S64-9. [DOI:10.1016/s01688278(03)00141-7] [PMID]

[3] Arif M, Al-Faleh FZ, Al-Frayh AR, Ramia S. Reduction in the prevalence of antibody to hepatitis A virus among young Saudi adults: Implications for hepatitis a vaccine. Saudi Journal of Gastroenterology. 1995; 1(2):93-6. [PMID]

[4] Moezzi M, Imani R, Khosravi N , Mobasheri M. [A study on hepatitis B vaccination coverage and $\mathrm{Hbs} A b$ effective titer in adults of chaharmahal va bakhtyari province, 2013 (Persian)]. Journal of Shahrekord University of Medical Sciences. 2014; 16(1):129-37. http://78.39.35.44/article1-1648-en.html

[5] Zadfettah F, Bolourian M, Sadegh A. [Postvaccination hepatitis B antibody titer on students of Ardebil college of dentistry (Persian)]. Iranian Journal of Medical Microbiology. 2016; 10(3):68-72. http://ijmm.ir/ article-1-522-fa.html

[6] Venkatakrishnan B, Zlotnick A. The structural biology of hepatitis B virus: Form and function. Annual Review of Virology. 2016;3(1):429-51. [DOI:10.1146/annurev-virology-110615-042238] [PMID] [PMCID]

[7] Corti D, Benigni F, Shouval D. Viral envelope-specific antibodies in chronic hepatitis B virus infection. Current Opinion in Virology. 2018; 30:48-57. [DOI:10.1016/j.coviro.2018.04.002] [PMID]

[8] MacLachlan JH, Cowie BC. Hepatitis B virus epidemiology. Cold Spring Harbor Perspectives in Medicine. 2015; 5(5):a021410. [DOI:10.1101/ cshperspect.a021410] [PMID] [PMCID]

[9] Tong S, Revill P. Overview of hepatitis B viral replication and genetic variability. Journal of Hepatology. 2016; 64(1 Suppl):S4-S16. [DOI:10.1016/j. jhep.2016.01.027] [PMID] [PMCID]

[10] Liaw YF, Chu CM. Hepatitis B virus infection.The Lancet. 2009; 373(9663):582-92. [DOI:10.1016/S0140-6736(09)60207-5] [PMID]

[11] Lok AS, Zoulim F, Dusheiko G, Ghany MG. Hepatitis B cure: From discovery to regulatory approval. Journal of Hepatology. 2017; 67(4):84761. [DOI:10.1016/j.jhep.2017.05.008] [PMID]

[12] Wasley A, Kruszon-Moran D, Kuhnert W, Simard EP, Finelli L, McQuillan $G$, et al. The prevalence of hepatitis $B$ virus infection in the United States in the era of vaccination. The Journal of Infectious Diseases. 2010; 202(2):192-201. [DOI:10.1086/653622] [PMID]

[13] Terrault NA, Lok ASF, McMahon BJ, Chang KM, Hwang JP, Jonas MM, et al. Update on prevention, diagnosis, and treatment of chronic hepatitis B: AASLD 2018 hepatitis B guidance. Hepatology. 2018; 67(4):1560-99. [DOI:10.1002/hep.29800] [PMID] [PMCID]

[14] Zuckerman JN. Protective efficacy, immunotherapeutic potential, and safety of hepatitis B vaccines. Journal of Medical Virology. 2006; 78(2):169-77. [DOI:10.1002/jmv.20524] [PMID]

[15] Hashemi SA, Moghadami M,Bagheri Lankarani K, Alborzi A, Mahbudi A. [The efficacy of hepatitis $B$ vaccination among school age children in Southern Iran (Persian)]. Iranian Red Crescent Medical Journal. 2010; 12(1):45. https://ircmj.com/index.php/IRCMJ/Vol12Issu1
[16] Sharifi Z, Milani S, Shooshtari MM. [Study on efficacy of hepatitis B immunization in vaccinated beta-thalassemia children in Tehran (Persian)]. Iranian Journal of Pediatrics. 2010; 20(2):211-5. [PMID] [PMCID]

[17] Zamani F, Fallahian F, Hashemi F, Shamsaei Z, Alavian SM. [Immune response to hepatitis $B$ vaccine in health-care workers (Persian)]. Saudi Journal of Kidney Diseases and Transplantation. 2011; 22(1):179-84. [PMID]

[18] Habibi F, Motavaselian AH. Evaluation of the hepatitis B antibody (Anti $\mathrm{HBs}$ ) level fallowing of vaccination among medical students in Islamic Azad University (Mashhad Branch) in 2013. Scientific Journal Management System. 2013; 3(1):1-10. http://www.iaujournals.ir/article_53119 3_4ea3cd50f7920e0f5ffd1a4dc470c78f.pdf

[19] Azami M, Ahmadi MRH, Sayehmiri K. [Hepatitis B vaccination efficacy in Iranian healthcare workers: A meta-analysis study (Persian)]. Hepatitis Monthly. 2017; 17(1): e37781. [DOI:10.5812/hepatmon.37781]

[20] Saffar H, Ajami A, Saffar MJ, Shojaei J, Sotudeh-Anvari M, Shams-Esfandabad $\mathrm{K}$, et al. [Prevalence of hepatitis B virus seromarkers in young adults vaccinated at birth; Impact on the epidemiology of hepatitis B infection in Iran (Persian)]. Hepatitis Monthly. 2014; 14(5):e17263. [DOI:10.5812/hepatmon.17263] [PMID] [PMCID]

[21] Ten Kate Q, Aanstoot HJ, Birnie E, Veeze H, Mul D. GADA persistence and diabetes classification. The Lancet Diabetes \& Endocrinology. 2016 4(7):563-4. [DOI:10.1016/S2213-8587(16)30103-6] [PMID]

[22] Sarkari B, Zargar M, Mohammad R, Asgarian S. [Prevalence of hepatitis $B$ antibodies in health-care workers in Yasuj hospitals (Persian)]. Armaghane Danesh. 2007; 11 (4):97-106. http://armaghanj.yums.ac.ir/ article-1-706-en.html

[23] Jouneghani AS, Chaleshtori MH, Khoshdel A, Kheiri S, Farrokhi E, Khalafian $\mathrm{P}$, Aliyari Z. Evaluation of response to hepatitis B vaccine in Iranian 6-18-year-old students. Journal of Research in Medical Sciences: The Official Journal of Isfahan University of Medical Sciences. 2017; 22:116. [DOI:10.4103/jrms.JRMS_204_17]

[24] Darvish MS, Zahedi MJ, Yazdani R. [Persistence of immune response af ter hepatitis B vaccination in medical students and residents (Persian)]. Archives Of Iranian Medicine. 2004; 7(1):37-40. https://www.sid.ir/en/ journal/ViewPaper.aspx?ID=4496

[25] Amini S, Andalibi S, Mahmoodi M. [Anti-HBs response and its protective effect in children and adults receiving hepatitis $B$ recombinant vaccine in Tehran (Persian)]. Iranian Journal of Medical Sciences. 2002; 27(3):101-5. https://ijms.sums.ac.ir/article_40260.html

[26] Momen Heravi M, Sharif AR, Moosavi SGA. [Evaluation of Anti HBs antibody in vaccinated personnels of Beheshti hospital in Kashan (Persian)]. KAUMS Journal. 2006; 10(1):11-14. http://feyz.kaums.ac.ir/ article-1-105-en.htm

[27] Khodaveisi M, Mohammadi N, A Omidi, Amini R. [Antibody titers of hepatitis $B$ in hamadan's nursing and midwifery students (Persian)]. Avicenna Journal of Nursing and Midwifery Care. 2010; 18(1):45-55. http:// nmj.umsha.ac.ir/article-1-1075-en.htm

[28] Bayas JM, Bruguera M, Vilella A, Bare ML, Prat A, Vidal J, et al. The vaccination of medical and nursing students against hepatitis $B$. Medicina Clinica. 1993; 101(1):8-11. [PMID]

[29] Janbakhsh A, Sayad B, Vaziri S, Aieni P. Serologic response to hepatitis $B$ vaccine in health care workers, Kermanshah, Iran. Journal of Research in Medical Sciences (JRMS). 2005; 10(3):147-9. https://www.sid.ir/en/ Journal/ViewPaper.aspx?ID=49907 
[30] Ferraz ML, Silva AE, Kemp VL, Cruz CN, Guimaraes RX. Evaluation of the immunological response to hepatitis $B$ vaccine in health care professionals. Revista da Associacao Medica Brasileira (1992). 1992; 38(1):5-8. [PMID]

[31] Afzali H, Sharif MR, Taghavi-Ardakani A, Momen-Heravi M, Salehi M, Jarchi $A$. [The evaluation of immunization against hepatitis $B$ vaccine among the health staff of Kashan University of Medical Sciences during 2012-2013 (Persian)]. KAUMS Journal (FEYZ). 2014; 18(3):253-9. http:// feyz.kaums.ac.ir/article-1-2285-en.pdf

[32] Rostami H, Farmani S, Mirzaee A, Ghorbanzadeh R. [Evaluating the rate of immune response for hepatitis $b$ vaccine in high risk personel (Persian)]. The Journal of Urmia Nursing and Midwifery Faculty. 2008; 6(4):179-82. http://unmf.umsu.ac.ir/article-1-78-en.html

[33] Baba Mahmoodi F. [Evaluation of hepatitis B antibody (HBS) levels in nursing staff of gaemshahr Razi hospital and it's variation with duration of immunity post HB vaccination (Persian)]. Journal of Mazandaran University of Medical Science. 2000; 10 (27) :48-53. http://jmums.mazums. ac.ir/article-1-300-en.html

[34] Haji BK, Rahimi A, Manssorifar S. [Measurement of serum antibody against hepatitis $b$ virus surface antigen (anti $\mathrm{Hbs} \mathrm{Ab}$ ) in vaccinated employees of Tohid Hospital in Sanandaj (Persian)]. Scientific Journal of Kurdistan University of Medical Sciences. 2001; 5(4):27-9. https://www. sid.ir/en/Journal/ViewPaper.aspx?ID=27126

[35] Perera J, Perera B, Gamage S. Seroconversion after hepatitis B vaccination in healthy young adults, and the effect of a booster dose. Ceylon Medical Journal. 2002; 47(1):6-8. [DOI:10.4038/cmj.v47i1.6396] [PMID]

[36] Heidari S, Rezatofighi SE, Roayaei-Ardakani M, Akhond MR. [Determination of hepatitis $B$ surface antibody and gamma interferon responsiveness in vaccinated personnel reffered to a health network in Dashtee Azadegan (Khozestan Province) (Persian)]. KAUMS Journal. 2016; 20(3):274-81. http://feyz.kaums.ac.ir/article-1-3090-en.html

[37] Nooshiravanpour P, Ramazenkhani A, Gashani M, Khodakarim S, Hatami H. [Immunity against hepatitis-B among freshman students at Shahid Beheshti university of medical sciences, academic year 2012-2013 (Persian)]. Research in Medicine. 2014; 38(3):176-80. http://pejouhesh. sbmu.ac.ir/article-1-1273-en.html

[38] Izadpanah A, Mashreghy Moghadam H, Ziaee M, Foadaldini M, Ebadian F. [Anti HBs level in nursing staff of Birjand university of medical sciences (Persian)] . Journal of Birjand University of Medical Sciences. 2008; 15(2):80-5. http://journal.bums.ac.ir/article-1-287-en.html 
This Page Intentionally Left Blank 